\title{
Measurement of the acoustic absorption coefficient of some local building materials for residential buildings using the Kundt tube method
}

\author{
M. Sylvain Djikou' ${ }^{1}$ C. Aristide Houngan², Malahimi Anjorin ${ }^{3}$, Antoine Vianou ${ }^{4}$, \\ Gérard Degan ${ }^{5}$ \\ 1, 2,3, ${ }^{4}$ Laboratory of Thermophysical Characterization of Materials and Energy Appropriation \\ (Labo-CTMAE) of the Polytechnic School of Abomey-Calavi (EPAC), 01 BP 2009, Cotonou, Benin \\ ${ }^{2}$ LARPET/ENSET/Lokossa/UNSTIM Multidisciplinary Research Laboratory of Technical Education \\ Abomey BP 133, Cotonou, Benin \\ ${ }^{5}$ Laboratory of Energetics and Applied Mechanics (LEMA) of the EPAC, 01 BP 2009, Cotonou, Benin \\ ${ }^{1}$ Corresponding author \\ E-mail: ${ }^{1}$ sylvain.djikou@epac.uac.bj, ${ }^{2}$ hounaris@yahoo.fr, ${ }^{3}$ malahimianjorin1@yahoo.fr, \\ 4avianou@yahoo.fr, ${ }^{5}$ ger_degan@yahoo.fr
}

Received 23 August 2018; accepted 3 September 2018 DOI https://doi.org/10.21595/vp.2018.20160

Check for updates

Copyright $(2018$ M. Sylvain Djikou, et al. This is an open access article distributed under the Creative Commons Attribution License, which permits unrestricted use, distribution, and reproduction in any medium, provided the original work is properly cited.

\begin{abstract}
Sound noise is a major societal problem, whose health, environmental and even economic impact is very important. According to the World Health Organization (WHO), noise is an acoustic phenomenon that produces an uncomfortable hearing sensation. Populations whose buildings are housed in areas at high risk of noise are exposed to multiple diseases resulting from noise pollution. To remedy this, it is important to think of choosing the right materials with higher acoustic absorption coefficient. The materials studied in this article are concrete, mortar, stabilized soil, which are commonly and most used materials in the construction of residential buildings. The present work consists of determining the sound absorption coefficient of each material indexed by the Kundt tube method in order to provide building technicians with the standards to be followed to improve the acoustic comfort of residential buildings. From the results obtained in this paper, it's obvious sound absorption coefficients peaks in the low frequencies between $100 \mathrm{~Hz}$ and $500 \mathrm{~Hz}$ for the three materials. These sound absorption coefficients peaks are accented respectively at 0.74 for the stabilized earth; 0.85 for mortar and 0.94 for concrete.
\end{abstract}

Keywords: sound absorption coefficient, buildings materials, acoustic comfort, noise reduction coefficient, Kundt tube.

\section{Introduction}

In the area of the building, noise from traffic, walking, conversation, equipment are the sources of annoyances that can go from a deterioration in the quality of life to direct effects on the health of occupants. As such, the fight against noise is an important issue which translates into regulations, acoustic standards that set minimum acoustic performance expected inside the buildings so as to provide the acoustic comfort for the occupants and users $[1,2]$.

However, the noise produced by industries, streets, construction sites, garages, handling sites, individuals or groups of individuals, and even aircraft become more troublesome or even harmful for to neighboring people according to the level where they are located. Indeed, the ear is adversely affected by noise level greater than $120 \mathrm{~dB}$ (decibels). This can lead to rupture of the eardrum [2]. As such, inhabitants of buildings located in the vicinity of the endless sources of noise are constantly exposed to unpleasant acoustic effects that will lead sooner or later diseases. To remedy this, it urges to think about the choice of the appropriate materials with a significant acoustic coefficient to ward off the harmful effects caused by sound rumors over the health of the population, during the construction of residential buildings in areas with high risk of noise.

For any building, contractors must check the standards on insulation against aerial noises and 
shock-related noises, insulation of facades, noise produced by technical equipment or reduction of some local reverberation [3-5].

To succeed in this, it is important to use relevant approaches among which the Kundt tube [6] method to identify local materials with significant acoustic coefficients [7] that can be used to improve the acoustic comfort of residential buildings.

\section{Materials and methods}

\subsection{Presentation of some materials}

- Concrete: sand mixture of sea + gravel + cement + water [1].

Dosage: sand 40 l; gravel 80 l; cement $350 \mathrm{~kg} / \mathrm{m}^{3}$ (1 pack); 401 water.

- Mortar: sea sand mix + cement + water [1].

Dosage: 2 wheelbarrows of sand from sea; 1 package of cement; 401 water.

- Stabilized earth: Earth + cement + water [1].

Dosage: 2 wheelbarrows stabilized $\left(1900 \mathrm{~kg} / \mathrm{m}^{3}\right) ; 25 \mathrm{~kg}$ of cement; 601 water.

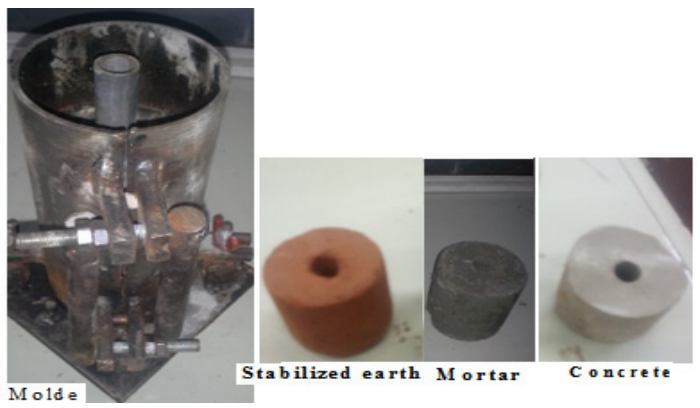

Fig. 1. Below shows the image of the samples tested

\subsection{Measuring the sound absorption coefficient using the Kundt tube}

This device is chosen for the characterization of the study materials because it has some advantages:

- The tested samples are small, manipulations are wealthier than in the anechoic and reverberating chambers to mobilize large areas of material.

- Measures are generally more accurate and offer a very good reproducibility [8].

Our device works with a micro explorer fixed at the end of a rod, which through a sliding movement, can measure the electrical quantities (maximum and minimum values of the voltage) that can be used to deduce acoustic reflection coefficients or acoustic absorption coefficients and acoustic impedances according to well-defined frequency values in the range $85 \mathrm{~Hz}<f<1700 \mathrm{~Hz}$. The existing devices on the market have one, two or four microphones all fixed allow to measure the acoustic absorption coefficients and the acoustic impedances on the ranges of varied frequencies.

Our device allows measurement frequency-by-frequency the acoustic absorption coefficient while for multi-microphone tubes the frequency range is scanned in a single measurement with more precisions [9].

The method chosen for our study is that of the single microphone. This choice is also justified by the reliability of the measurements made; the simplicity of the system (no need for a microphone calibration as in the case of the microphone doublet method and the simplest determination of the desired phonic parameters (does not require the use of the transfer function). In conclusion, our device does not have a peculiarity compared to existing ones; we designed and realized it ourselves based on existing models to reach our objectives of applied research 


\subsubsection{Description of the device}

To measure the sound absorption coefficient, the Kundt tube is used. The experimental apparatuses include the Test-tube made of PVC cylindrical rigid tube (Homogeneous, isotropic, length $L=1 \mathrm{~m}$ with inner diameter $D=10 \mathrm{~cm}$ ) and have very low absorption coefficient, Speaker (DX; $8 \Omega, 2,5 \mathrm{~W}$ ) which represent the sound source, a one-inch dynamic Microphone Electret condenser, powered by a $9 \mathrm{~V}$ battery; pre-magnified and amplified by an BO SOUND amplifier, Bicourbe oscilloscope (GW-INSTEK GDS-2104 or RAS-820 Mark) which measure the maximum and minimum electrical voltage signal picked by the microphone and low frequency generator (LODESTAR FG-20208) which generates the sinusoidal signals. Fig. 2 and 3 show the experimental device and the microphone used.

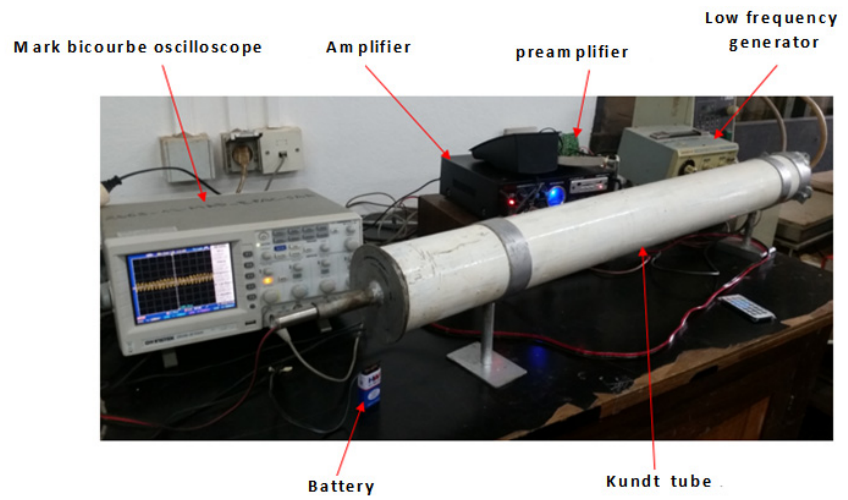

Fig. 2. Experimental device with Kundt's tube

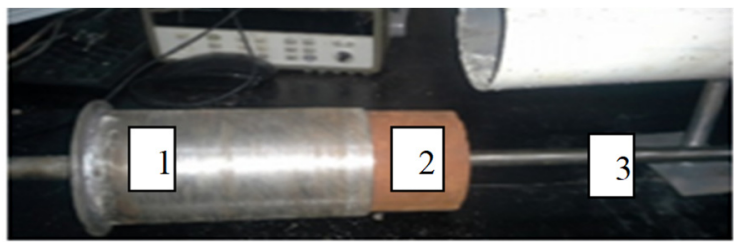

Fig. 3. Loading the material to be tested.

1. Sample carrier; 2. Stabilized earth sample; 3 . Rod carrying the microphone

\subsubsection{The Kundt tube principle}

The Kundt tube principle is shown in Fig. 4.

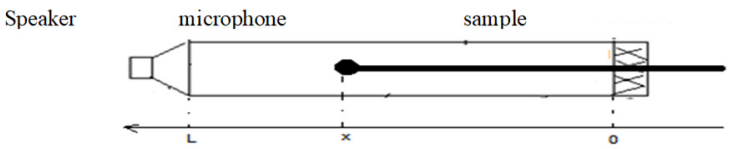

Fig. 4. Schema modelled Kundt tube [9]

\subsection{Method used to determine the acoustic absorption coefficient}

Sound absorption coefficient describes the efficiency of the material or the surface.

The Kundt tube is closed at one end by a speaker while the other end is blocked by the material under test. So, the principle of operation is the following [7].

A low frequency generator (PFG) is plugged into the speaker of the Kundt tube. The exploring microphone is then connected to the data acquisition system or the oscilloscope. There is a cap consisting of the material under test on the end of the tube, opposite the speaker. The frequency 
issued by the PFG is set on a normalized value. Next, the exploring microphone is moved in the Kundt tube. Then, the value of the maximum amplitude $U_{\max }$ and that of the minimum amplitude $U_{\min }$ is noted.

We then compute the value of the reflection coefficient $g$ according to Eq. (1) and that of the absorption coefficient $\alpha$ of the material tested according to the Eq. (3).

The reflection coefficient $\mathrm{g}$ of materials is then obtained through:

$g=\left(\frac{U_{\max }-U_{\min }}{U_{\max }+U_{\min }}\right)^{2}$

where $U_{\max }$ is the maximum electric voltage measured at the terminals of the exploring microphone and $U_{\min }$ is the minimum voltage measured at the terminals of the same microphone.

However, we have the following:

$g+\alpha=1$,

from which we deduce that:

$\alpha=1-g$.

\section{Results and discussion}

\subsection{Results}

The results obtained after the experiments are as follows.

Table 1. The frequency of concrete absorption coefficient

\begin{tabular}{|c|c|c|c|c|c|c|c|c|c|c|c|c|c|}
\hline$f(\mathrm{~Hz})$ & 100 & 125 & 160 & 200 & 250 & 320 & 400 & 500 & 640 & 800 & 1000 & 1250 & 1600 \\
\hline$U_{\max }$ & 1,74 & 1,72 & 1,68 & 1,62 & 0,67 & 1,7 & 1,3 & 1,0 & 1,3 & 1,12 & 0,64 & 0,38 & 0,26 \\
\hline$U_{\min }$ & 0,80 & 0,70 & 0,48 & 0,46 & 0,41 & 0,38 & 0,22 & 0,26 & 0,32 & 0,33 & 0,215 & 0,215 & 0,20 \\
\hline$g$ & 0,14 & 0,18 & 0,31 & 0,31 & 0,06 & 0,40 & 0,50 & 0,34 & 0,37 & 0,30 & 0,25 & 0,08 & 0,02 \\
\hline$\alpha$ & 0,86 & 0,82 & 0,69 & 0,69 & 0,94 & 0,60 & 0,50 & 0,66 & 0,63 & 0,70 & 0,75 & 0,92 & 0,98 \\
\hline
\end{tabular}

Table 2. The frequency of mortar absorption coefficient

\begin{tabular}{|c|c|c|c|c|c|c|c|c|c|c|c|c|c|}
\hline$f(\mathrm{~Hz})$ & 100 & 125 & 160 & 200 & 250 & 320 & 400 & 500 & 640 & 800 & 1000 & 1250 & 1600 \\
\hline$U_{\max }(\mathrm{V})$ & 0,96 & 1,30 & 1,68 & 1,80 & 0,48 & 0,36 & 0,62 & 0,48 & 0,42 & 0,26 & 0,92 & 0,20 & 0,18 \\
\hline$U_{\min }(\mathrm{V})$ & 0,42 & 0,28 & 0,24 & 0,44 & 0,18 & 0,16 & 0,16 & 0,161 & 0,16 & 0,14 & 0,24 & 0,14 & 0,14 \\
\hline$g$ & 0,15 & 0,42 & 0,56 & 0,37 & 0,21 & 0,15 & 0,35 & 0,25 & 0,20 & 0,09 & 0,34 & 0,03 & 0,02 \\
\hline$\alpha$ & 0,85 & 0,58 & 0,44 & 0,67 & 0,79 & 0,85 & 0,65 & 0,75 & 0,80 & 0,91 & 0,66 & 0,97 & 0,98 \\
\hline
\end{tabular}

Table 3. The frequency of stabilized earth absorption coefficient

\begin{tabular}{|c|c|c|c|c|c|c|c|c|c|c|c|c|c|}
\hline$f(\mathrm{~Hz})$ & 100 & 125 & 160 & 200 & 250 & 320 & 400 & 500 & 640 & 800 & 1000 & 1250 & 1600 \\
\hline$U_{\max }(\mathrm{V})$ & 1,70 & 1,72 & 1,70 & 1,68 & 1,40 & 1,36 & 0,68 & 1,28 & 1,66 & 0,70 & 0,86 & 0,36 & 0,34 \\
\hline$U_{\min }(\mathrm{V})$ & 1,06 & 0,86 & 0363 & 0,66 & 0,29 & 0,225 & 0,22 & 0,20 & 0,31 & 0,20 & 0,24 & 0,20 & 0,22 \\
\hline$g$ & 0,05 & 0,11 & 0,19 & 0,19 & 0,43 & 0,51 & 0,26 & 0,53 & 0,47 & 0,31 & 0,32 & 0,08 & 0,05 \\
\hline$\alpha$ & 0,95 & 0,89 & 0,81 & 0,81 & 0,57 & 0,49 & 0,74 & 0,47 & 0,53 & 0,69 & 0,68 & 0,92 & 0,95 \\
\hline
\end{tabular}

\subsection{Discussion}

The Kundt tube used to carry out the measures has the following dimensions: length $L=1 \mathrm{~m}$; diameter $D=10 \mathrm{~cm}$ and allows a frequency range of $a / 4 L<f<a / 2 D[9,10]$ that is $85 \mathrm{~Hz}<f<1700 \mathrm{~Hz}$; From this perspective, from this point of view we manipulated with the standard third octave frequencies located in the main frequency domain indexed. Fig. 5 shows the 
coefficient of acoustic absorption of the three tested materials.

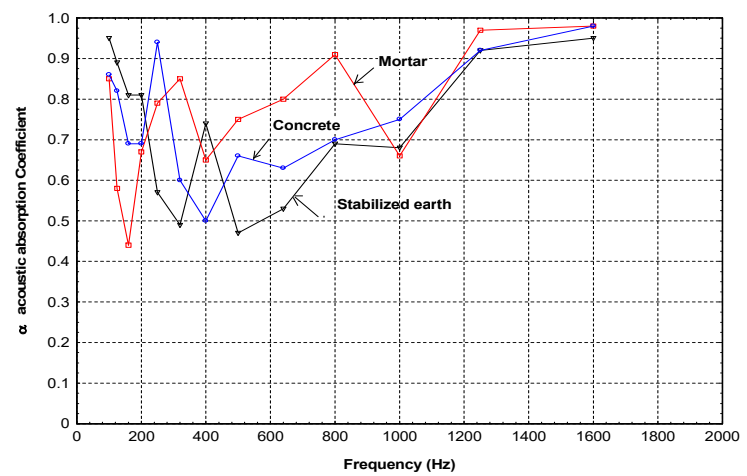

Fig. 5. Measurement of acoustic absorption for concrete, mortar and stabilized earth using the Kundt Tube

From the curves, there are some obvious sound absorption coefficients peaks in the low frequencies between $100 \mathrm{~Hz}$ and $500 \mathrm{~Hz}$ for the three materials. These sound absorption coefficients peaks are accented respectively at 0.74 for the stabilized earth; 0.85 for mortar and 0.94 for concrete and are in line with the literature for other similar materials [11]. Similarly, the curves of the curves are arranged in increasing order towards the high frequencies (from $600 \mathrm{~Hz}$ to $1600 \mathrm{~Hz}$ ). Indicating the sound absorbing properties of materials by using the absorption coefficient values at different frequency ranges might be too complex. To solve this problem, the ability of a material to absorb sound is generally calculated using a single value: the noise reduction coefficient $(T)[12,13]$. The $(T)$ value can be calculated using formula:

$T=\frac{\alpha_{250}+\alpha_{500}+\alpha_{1000}+\alpha_{1600}}{4}$.

From this point of view, to interpret these curves, the histogram of $T$ is made according to the materials under study (Table 4).

The acoustic reduction coefficients calculated (Table 4) and represented by the histogram (Fig. 6) show that the most absorbent material is concrete, followed by mortar and stabilized earth.

Table 4. The noise reduction coefficient for materials

\begin{tabular}{|c|c|}
\hline Materials & Noise reduction coefficient $(T)$ \\
\hline Concrete & 0,833 \\
\hline Mortar & 0,795 \\
\hline Stabilized earth & 0,668 \\
\hline
\end{tabular}

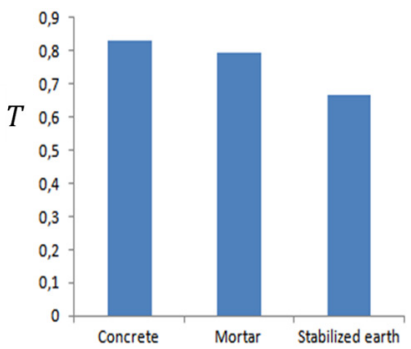

Fig. 6. Noise reduction coefficient for concrete, mortar and stabilized earth

\subsection{Computing Error margin on results obtained}

The instructions read on the digital oscilloscope used as far as measurement accuracy is 
concerned are as follows: Precision $= \pm\left(3 \%\right.$. $\left.U_{\text {mes }}+0,05 \mathrm{div} . \mathrm{Cal} / \mathrm{div}\right)$; with $\mathrm{Cal} / \mathrm{div}=$ the vertical sensitivity (we realized our measures on $1 \mathrm{~V} / \mathrm{div}$ ) so we have:

$\Delta U_{\max }= \pm\left(0,03 U_{\text {maxmes }}+0,05 * 1\right) \mathrm{V}, \Delta U_{\min }= \pm\left(0,03 . U_{\text {minmes }}+0,05 * 1\right) \mathrm{V}$,

according to Eq. (3) we have: $\Delta \alpha / \alpha=\Delta g / g$.

And by applying the logarithmic method to Eq. (1) and taking the upper limit of error on the measurement of tension there comes:

$\frac{\Delta g}{g}=\frac{4 U_{\max } U_{\min }}{U_{\max }^{2}-U_{\min }^{2}}\left(\frac{\Delta U_{\min }}{U_{\min }}+\frac{\Delta U_{\max }}{U_{\max }}\right), \quad \frac{\Delta \alpha}{\alpha}=\frac{4 U_{\max } U_{\min }}{U_{\max }^{2}-U_{\min }^{2}}\left(\frac{\Delta U_{\min }}{U_{\min }}+\frac{\Delta U_{\max }}{U_{\max }}\right)$.

Tension measurement accuracy varies from 0,01 to $0,15 \%$ according to the frequencies.

\section{Conclusions}

The Kundt tube is used to measure the minimum and maximum voltages in the presence of each material studied: $10 \mathrm{~cm}$ thick concrete; $10 \mathrm{~cm}$ thick mortar and $10 \mathrm{~cm}$ thick stabilized earth. These values of measured voltages have helped to compute the coefficient of sound absorption of each indexed material. In conclusion, it is worth noting that the three materials are good absorbent $(\alpha \geq 0,5)$ but the best absorbing material among the three under review is the concrete. Further studies will be carried out with other construction materials in order to have a data bank on the best absorbent of sound noise to ensure the acoustic comfort in residential buildings.

\section{References}

[1] Gobain S. Introduction to Building Acoustics, 2012.

[2] Houngan A. C., Awanto C., Anjorin M., Djossou A. A., Vianou A. Phonic characterization of three local materials used in the construction of the habitat in Benin. Sciences des Structures et de la Matière, Vol. 1, 2013, p. 40-49.

[3] Standardization Office (NBN) S01-400-1: Acoustic Criteria for Residential Buildings, 1st quarter 2007.

[4] Pascal J.-C. Vibration and Acoustics 1. ENSIM 2A, 2007-2008.

[5] Glé P. Building materials acoustics based on fibers and plant particles - characterization, modeling and optimization tools. Civil Engineering and Building Laboratory, National School of Public Works, 2013, p. 389.

[6] Grégoire S. Acoustic Behavior of Church Wall Coverings. Master 2 Cultural Heritage Materials.

[7] Measurement of sound absorption coefficient at Kundt tube. Lyon INSA, National Institute of Applied Sciences of Lyon, Acoustic Vibration Laboratory, France.

[8] Jeulin S. A. V. Propagation of the waves; Kundt tube with analog outputs. Ref 222 044., 27019 Evreux Cedex, France.

[9] Léwy S. Industrial Acoustics and Aeroacoustics. Chapter 7: Acoustic Wall Impedance. Hermes Sciences Publications, Paris, 2001.

[10] Dutilleux G. In Situ Measurement of Sound Absorption of Materials in Buildings. The National Institute of Applied Sciences of Lyon, 1999.

[11] Xiao Dan Z., Wang X., Yong Jie Y. Enhancing low-frequency sound absorption of micro-perforated panel absorbers by combining parallel mechanical impedance. Applied Acoustics, Vol. 130, 2018, p. 300-304.

[12] Ancuţa Elena T., Horaţiu V., Timea G., Ovidiu V. Improved sound absorption properties of polyurethane foam mixed $\backslash$ with textile waste. Sustainable Solutions for Energy and Environment, Bucharest, Romania, 2015.

[13] Sukontasukkul P. Use of crumb rubber to improve thermal and sound properties of pre-cast concrete panel. Construction and Building Materials, Vol. 23, 2009, p. 1084-1092. 